\title{
14. COVID-19: Trade restrictions are worst possible response to safeguard food security
}

\author{
Joseph Glauber, David Laborde, Will Martin, and Rob Vos
}

As COVID-19 spreads around the globe, fears of a deep global recession are mounting. Some also fear that food supplies may start running short, especially if supply chains are disrupted. Others fear that agricultural production may be disrupted by containment measures that restrict workers from harvesting and handling crops.

While we should take these concerns seriously - especially for fruits and vegetables, which have complex supply chains, or foods sold primarily through restaurants - they should not be overstated either, especially not for basic staples such as rice, wheat, and maize. Global markets are well supplied, stocks are healthy, production of key staples is unlikely to be disrupted, and prices have remained relatively stable. Trade is allowing production to move from areas of surplus to areas of shortage, avoiding the drastic shortages and food insecurity associated with reliance only on local production.

But there will be serious threats to poor people's access to food as a consequence of lost income from lockdowns and other restrictions. These should be addressed through measures that help maintain access to food, rather than through policies like export bans that may further threaten that access.

The food price crisis of 2007-2008 shows, however, that policy concerns about food availability can easily turn into a serious price crisis. At the time, some grain-exporting countries responded by imposing export restrictions, which pushed up world market prices of staples, leading other grain producers to also limit exports in efforts to insulate their consumers from the initial food price rises. Food-importing countries, worried about the higher cost of food, in turn lowered import tariffs on food, supporting demand but keeping upward pressure on world prices. As a result, instead of containing price increases, these policy responses only drove world market prices higher. In the case of rice, these policy responses contributed almost half of the world price surge in 2007-2008.

Unfortunately, once again several countries responded by implementing export restrictions, though fortunately many of these were temporary. See our online tracker. Kazakhstan, for instance, suspended exports of several cereal products, as well as oilseeds and vegetables, until June 30 . Viet Nam halted granting rice export certificates through the end of March, but has since begun granting them again. These restrictions, even if temporary, seem entirely unnecessary. Both countries produce far more than they consume and have ample stocks. An export ban by two key exporters would limit global supply and will certainly push up world prices of staple foods if others follow suit.

How does the present situation compare with 2007-2008? Will we see a repeat of the same policy mistakes? 


\section{FIGURE 1 Staple crop stock-to-use ratios, 2008 and 2019}

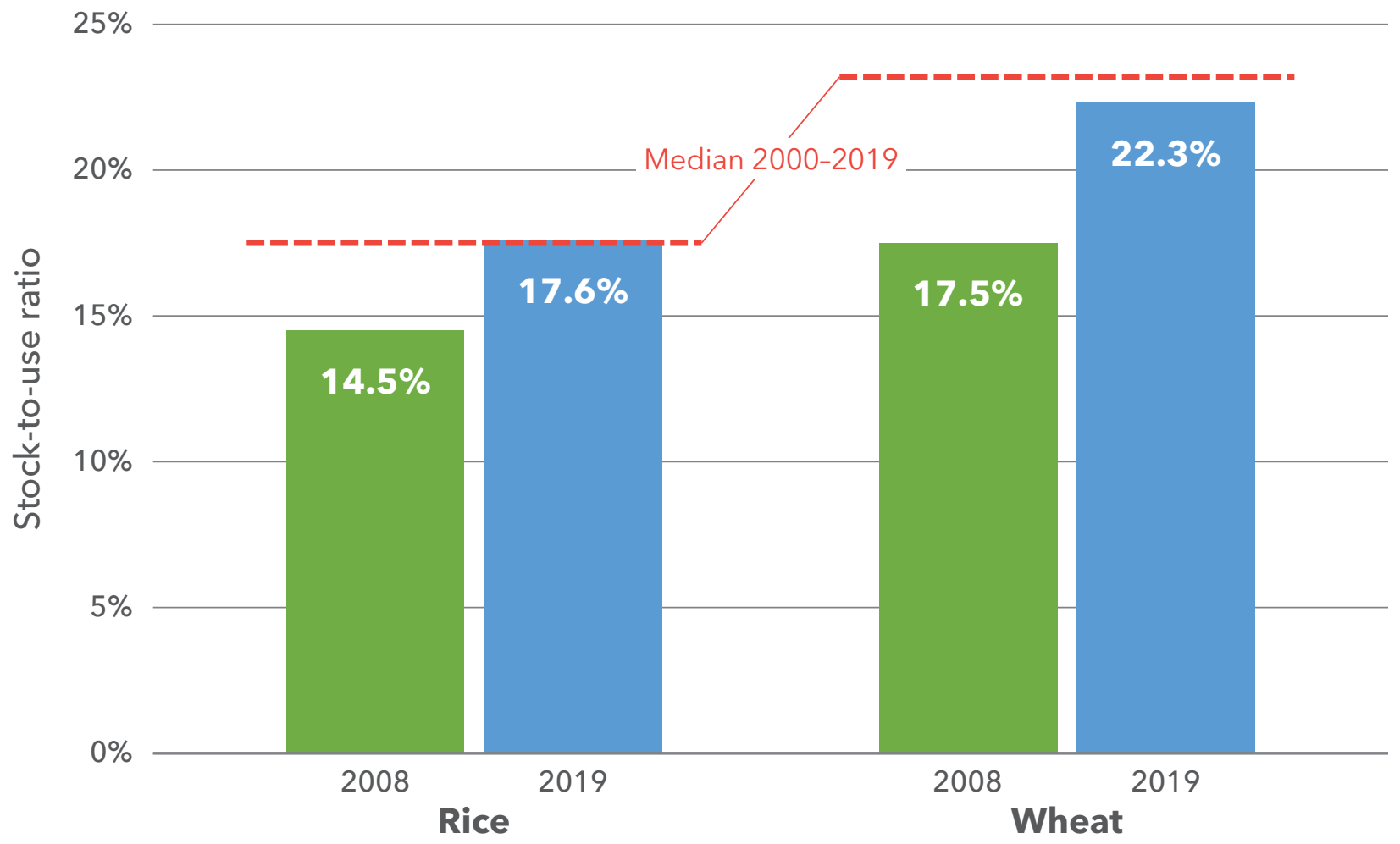

Source: Authors' computation using USDA-PSD data.

\section{Some key facts}

There is no shortage of staple food inventories. The stock-to-use ratio is a critical indicator of the vulnerability of world food markets to shocks. Excluding China, the current global stock-to-use ratios are close to their "normal value" (the median level of the last two decades), and substantially higher than in 2008 (Figure 1), when markets were tight. The sufficiency of inventories explains in good part the relative price stability in the markets for staples. The underlying situation is better than suggested by these statistics when also considering China's inventories of rice and wheat, which are sufficient for 10 to 13 months of domestic consumption.

Harvests are expected to be good. The US Department of Agriculture projects an increase in global wheat production of $5 \%$, while rice production is projected to remain about the same as in 2019. Production of these key staples is unlikely to suffer disruptions from the COVID-19 crisis - at least in major producing countries - since much of it is mechanized, requiring relatively little labor input, and takes place in areas with dispersed, already socially distanced, rural populations. Similarly, there is low probability of disruptions to international transport and distribution of these key staples which, being dry bulk commodities, can be loaded, shipped, and discharged with minimum humanto-human interaction. 
World exports are heavily concentrated. Russia, the European Union, the United States, Canada, and Ukraine together are likely to account for $75 \%$ of all wheat exports in 2019-2020. It therefore matters a great deal what governments of these countries do. So far, only Kazakhstan, which has a $3 \%$ share in global wheat exports, has announced export restrictions. However, Russia is now also reportedly considering a ban on wheat exports. The rice market is equally concentrated, with $75 \%$ of exports coming from the largest five exporters, and nearly a quarter from India alone. Viet Nam's world market share is $16 \%$, and as noted above it has suspended new export licenses. India's stockto-use ratio for rice, however, stands at an historic high of $34 \%$ and prospects for the 2020 harvest are good, such that it should have no reason to consider export restrictions, although some concerns have been expressed about difficulties moving products domestically.

\section{What should be done?}

The present outlook for staple food markets is much brighter than it was during the 2007-2008 price spike. Hence, imposing trade restrictions now would be even more misguided than it was in 2008. Rather, such policies could become the problem if Viet Nam and Kazakhstan maintain barriers and other countries follow in their footsteps. If they do, it could trigger food price spikes and speculative behavior in agricultural commodity markets. The world's poor would be the ones bearing the brunt.

Instead, trade channels should be kept open so that international markets can play an instrumental role in in avoiding food shortages and mitigating the inevitable global economic downturn.

Major exporters and importers of staple foods should agree to desist from imposing trade barriers in response to the COVID-19 pandemic. Rather, as we wrote in a previous blog post, the focus should be on measures that will help stave off a global recession and minimize a further rise in food insecurity that way. For this, governments will need to provide fiscal stimulus, including resources to contain the spread of the disease and ensure adequate healthcare is available, as well as additional social protection to compensate workers and families affected by the virus and by containment measures.

Originally published March 27, 2020. 